\title{
Enzyme-Linked Immunosorbent Assay for Detection of Serum Antibodies to Pasteurella haemolytica Cytotoxin (Leukotoxin) in Cattle†
}

\author{
DEREK A. MOSIER, ${ }^{1 *}$ ANTHONY W. CONFER,${ }^{1}$ STEPHEN M. HALL,${ }^{1}$ MARTHA J. GENTRY, ${ }^{2}$ \\ AND ROGER J. PANCIERA ${ }^{1}$ \\ Department of Veterinary Pathology ${ }^{1}$ and Department of Veterinary Parasitology, Microbiology, and Public Health, ${ }^{2}$ \\ College of Veterinary Medicine, Oklahoma State University, Stillwater, Oklahoma 74078
}

Received 13 January 1986/Accepted 28 April 1986

\begin{abstract}
An enzyme-linked immunosorbent assay (ELISA) was developed for detection of bovine serum antibodies to the cytotoxin (leukotoxin) of Pasteurella haemolytica. A partially purified, cytotoxic, and immunogenic protein obtained from supernatants of logarithmic-phase $P$. haemolytica was used as the ELISA antigen. Preadsorption of sera with various cytotoxic, somatic, and capsular antigen preparations demonstrated that the assay was specific for anticytotoxin antibodies. ELISA anticytotoxin titers had a strong, significant correlation to cytotoxin-neutralizing-antibody titers. The ELISA, however, was more rapid and allowed for greater numbers of samples to be run than did the neutralization technique. ELISA anticytotoxin titers were high in cattle vaccinated with a live $P$. haemolytica vaccine, whereas unvaccinated cattle and cattle receiving a $P$. haemolytica bacterin had low ELISA anticytotoxin titers. A significant positive correlation between ELISA titers and resistance to experimental bovine pneumonic pasteurellosis was present.
\end{abstract}

Bovine pneumonic pasteurellosis is a severe fibrinous pneumonia of feedlot cattle usually associated with infection by Pasteurella haemolytica biotype A, serotype $1(5,16,17)$. Various approaches used to prevent the disease have proven largely unsuccessful, and pneumonic pasteurellosis continues to be a major problem for the feedlot industry $(16,19)$.

Recent studies have concentrated on defining the role played by humoral immunity in resistance to pneumonic pasteurellosis. Clinical use of $\boldsymbol{P}$. haemolytica bacterins has not proven effective $(1,18,20)$. Cattle given bacterins developed an antibody response to somatic antigens, but this response did not consistently result in protection against $\boldsymbol{P}$. haemolytica challenge $(8,14)$. Live $P$. haemolytica vaccines given by aerosol or parenteral routes, however, resulted in both increased antibody titers to somatic antigens and enhanced resistance to experimental challenge (22). Similarly, enhanced resistance to challenge was noted in calves with prior natural exposure to the organism (9). Further studies with live $P$. haemolytica vaccines suggested a possible protective role for capsular antigens (8). Others have indicated that a neutralizing antibody to a $P$. haemolytica cytotoxin (leukotoxin) may play a role in increased protection against pneumonic pasteurellosis $(4,14,24)$.

Cytotoxin has been incriminated in the pathogenesis of pneumonic pasteurellosis through its toxicity for ruminant alveolar macrophages and peripheral blood leukocytes (2, 23). Antibody to cytotoxin has previously been measured only by labor-intensive cytotoxin neutralization assays. The purposes of this study were to develop an enzyme-linked immunosorbent assay (ELISA) to detect serum antibody to partially purified cytotoxin, to compare antibody responses detected by ELISA to those detected by neutralization

\footnotetext{
* Corresponding author.

$\dagger$ Journal article no. 4928 of the Oklahoma Agricultural Experiment Station.
}

assays, and to determine the potential of the ELISA as a predictor of resistance to experimental pneumonic pasteurellosis.

\section{MATERIALS AND METHODS}

Serum samples. Serum samples were obtained from 5- to 8-month-old calves which had been used in previous experiments to evaluate the effects of various vaccines on resistance to pneumonic pasteurellosis $(9,10,22)$. On days 0 and 7 , each calf was vaccinated subcutaneously with phosphatebuffered saline (PBS), a bacterin consisting of $10^{9} \mathrm{CFU}$ of Formalin-killed $P$. haemolytica in an aluminum hydroxide adjuvant, or $5 \times 10^{9} \mathrm{CFU}$ of live $P$. haemolytica $(10,11,22)$. Serum samples were collected on days $0,7,14$, and 21 and stored at $-20^{\circ} \mathrm{C}$. On day 21 , calves were experimentally challenged by transthoracic injection with $5 \mathrm{ml}$ of a $P$. haemolytica suspension in PBS containing approximately $10^{9} \mathrm{CFU} / \mathrm{ml}$ (21). On day 25 , calves were sacrificed, and lung lesions were evaluated to determine the extent of lung resistance to challenge exposure (22). Numerical scores were awarded on the basis of morphologic criteria, which included the size of the lesion and the degree of extension of inflammation from the original lesion site. A maximum score of 20 represented a severe lesion and lack of resistance, whereas lower scores corresponded to increased resistance. A total of 12 calves from each vaccination group were used in the study.

Serologic evaluation. Antibodies to somatic antigens of $P$. haemolytica were determined by a quantitative fluorometric immunoassay (FIAX; International Diagnostic Technology, Santa Clara, Calif.) with Formalin-killed 22-h cultures of $P$. haemolytica serotype 1 as the antigens (6).

Serum cytotoxin neutralization titers were determined as previously described $(4,14,24)$. In general, these determinations were made by preincubation of serial twofold dilutions of test sera with crude cytotoxin, followed by 


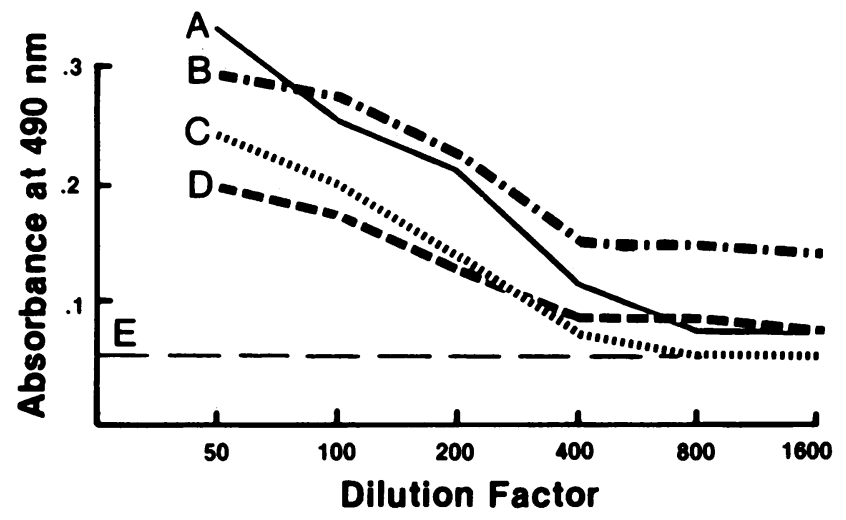

FIG. 1. $A_{490} \mathrm{~s}$ of serial dilutions of the following bovine serum samples: A, 476; B, 601; C, 634; and D, 621. E, PBS control $\left(A_{490}\right.$, 0.057).

cytotoxicity assays that measured cell viability as ${ }^{51} \mathrm{Cr}$ release from bovine leukocytes.

Anticytotoxin ELISA. The antigen used in the ELISA was a partially purified cytotoxic protein obtained from supernatants of logarithmic-phase cultures of $P$. haemolytica (D. A. Mosier, B. A. Lessley, A. W. Confer, S. M. Antone, and M. J. Gentry, submitted for publication). The protein was separated from crude $\boldsymbol{P}$. haemolytica supernatants by anionexchange chromatography, gel filtration, and chromatofocusing and was designated as partially purified cytotoxin. Sodium dodecyl sulfate-polyacrylamide gel electrophoresis and immunoblotting of partially purified cytotoxin revealed two antigenic bands when the cytotoxin was reacted with bovine antiserum to live $P$. haemolytica which had been adsorbed with Formalin-killed bacteria to remove antibody to capsular and somatic antigens.

Optimal conditions for the ELISA were determined from preliminary experiments with antigen coating concentrations of $0.01,0.1$, or $1 \mu \mathrm{g}$ of antigen per well, serum dilutions of $1: 50$ to $1: 1,600$, and conjugate dilutions of $1: 200$ and $1: 400$.

For routine assays, $100 \mu \mathrm{l}$ of antigen diluted to $10 \mu \mathrm{g} / \mathrm{ml}$ in carbonate buffer (pH 9.6) was placed in each well of 96-well polystyrene plates (Nunc, Roskilde, Denmark), and the plates were then incubated overnight at room temperature on a rocker platform. The plates were washed three times with PBS containing 0.05\% Tween 20 (PBS-Tween). For each sample, $100 \mu$ l of a 1:400 serum dilution in PBS-Tween containing $1 \%$ bovine serum albumin was added to duplicate wells and incubated for $1 \mathrm{~h}$. Following three washes with PBS-Tween, $100 \mu$ l of a 1:200 dilution of horseradish peroxidase-conjugated, affinity-purified, anti-bovine immunoglobulin G in PBS-Tween-1\% bovine serum albumin was placed in each well. After $1 \mathrm{~h}$ of incubation, the plates were washed six times with PBS-Tween. For color development, $100 \mu$ l of substrate containing phenylenediamine and hydrogen peroxide in phosphate-citric acid buffer was added to each well, and the plates were incubated for $45 \mathrm{~min}$ in the dark. The reaction was stopped by the addition of $50 \mu$ of $2.5 \mathrm{M} \mathrm{H}_{2} \mathrm{SO}_{4}$ to each well, and the $A_{490}$ was determined on a manual ELISA reader (Bio-Tek, Burlington, Vt.). The reported $A_{490}$ for each sample was the average of duplicate wells. To compare samples from different plates, we standardized $A_{490}$ readings on the basis of a positive control (serum from a steer hyperimmunized with live $P$. haemolytica) and a negative control (PBS), both included on each plate.

Adsorption experiments. Selected sera were used to study the specificity of the ELISA by preadsorption of the sera with several $P$. haemolytica antigens. For each sample, 100 $\mu$ l of serum was diluted 1:200 in PBS-Tween-1\% bovine serum albumin and then incubated with an equal volume of partially purified cytotoxin, a saline extract of $P$. haemolytica (15), Formalin-killed $P$. haemolytica, or PBS. Cytotoxin and capsular extract were used in concentrations of $1,000,100,10$, and $1 \mu \mathrm{g} / \mathrm{ml}$, whereas Formalin-killed bacteria were used at $10^{10}, 10^{9}, 10^{8}$, and $10^{7} \mathrm{CFU}$ equivalents, as determined spectrophotometrically (6). Mixtures were incubated overnight at $4^{\circ} \mathrm{C}$ on a rocker platform in 96-well, round-bottom tissue culture plates (Corning Glass Works, Corning, N.Y.). Adsorbed sera were then assayed by the ELISA as described above.

Statistical evaluation. Anticytotoxin antibodies were quantitated by the ELISA. These values were then compared with FIAX (somatic antigen) titers, cytotoxin neutralization titers, and lesion scores. Linear correlation among these variables was evaluated by the Pearson product-moment, Spearman, and Kendall tau correlations (Statistical Analysis System, Cary, N.C.). Group means for the different vaccinates were compared by multiple $t$ tests. A $t$ test for equal and unequal variances was calculated for the mean titers for each of the comparisons. An $F$ statistic was calculated to determine whether unequal variances were present. If the probability of $\boldsymbol{F}$ was $<0.05$, unequal variances were used in calculating $t$ test values.

\section{RESULTS}

Serial twofold dilutions of four bovine serum samples from 1:50 to 1:1,600 gave absorbance readings typical of an antibody response curve (Fig. 1). Preadsorption of one of the serum samples with PBS or various concentrations of a saline extract of $\boldsymbol{P}$. haemolytica or Formalin-killed $\boldsymbol{P}$. haemolytica had no effect on the cytotoxin antibody response. Preadsorption of the same serum sample with cytotoxin, however, resulted in dramatic decreases in the cytotoxin antibody response at the two highest concentrations of cytotoxin (Fig. 2).

In calves vaccinated with live $\boldsymbol{P}$. haemolytica, there was a marked increase in ELISA-detected antibody to cytotoxin (ELISA cytotoxin antibody) (Fig. 3). From days 0 to 21, the bacterin group had a small, insignificant $(P>0.05)$ increase in the ELISA cytotoxin antibody response as compared with the PBS group. During the same period, the ELISA cytotoxin antibody response for the PBS group remained relatively constant. On days 7,14 , and 21 , a significant difference $(P<0.05)$ was seen between the responses of the live-vaccine group and both the bacterin and PBS groups. No significant difference $(P>0.05)$ was present between the mean antibody responses for the bacterin and PBS groups on any day.

The means and standard deviations for day-21 samples for the ELISA cytotoxin antibody response, cytotoxin neutralization titer, FIAX titer, and lesion score for each vaccine group are given in Table $1 . t$ tests between these three groups showed a significant difference $(P<0.0001)$ between the means regardless of which of the four parameters was used as the dependent variable. The results of $t$ tests between groups for each parameter indicated that ELISA cytotoxin antibody responses and cytotoxin neutralization titers for the live-vaccine group were significantly different $(P<0.05)$ from those for both the bacterin and PBS groups. A significant difference was not detected between bacterin and PBS group mean responses. For FIAX titers and lesion scores, a 
significant difference $(P<0.05)$ was present between the means of all three groups.

Correlation coefficients $(r)$ and probabilities $(P)$ for all samples organized by parameter are given in Table 2 . Correlations of ELISA cytotoxin antibody responses with cytotoxin neutralization titers, FIAX titers, and lesion scores were all significant at $P<0.01$. The strongest correlation was between the ELISA cytotoxin antibody response and cytotoxin neutralization titers; whereas the lowest was between the ELISA cytotoxin antibody response and FIAX titers. As an indicator of resistance to pneumonic pasteurellosis, the ELISA correlated better with lesion scores than did the FIAX. Cytotoxin neutralization titers had the best correlation with lesion scores of all the parameters examined. Significant correlations were not obtained between any parameters when samples were evaluated within individual vaccine groups.

\section{DISCUSSION}

The result of this study was the development of a primary binding immunoassay (ELISA) which is suitable for screening large numbers of bovine serum samples for antibody to $P$. haemolytica cytotoxin. Previously reported ELISAs for $P$. haemolytica have used sodium salicylate extracts $(3,12)$, KSCN extracts (26), or saline extracts (7) of $P$. haemolytica as antigens. The assay in the current report is the first direct binding assay that uses a partially purified cytotoxic $P$.

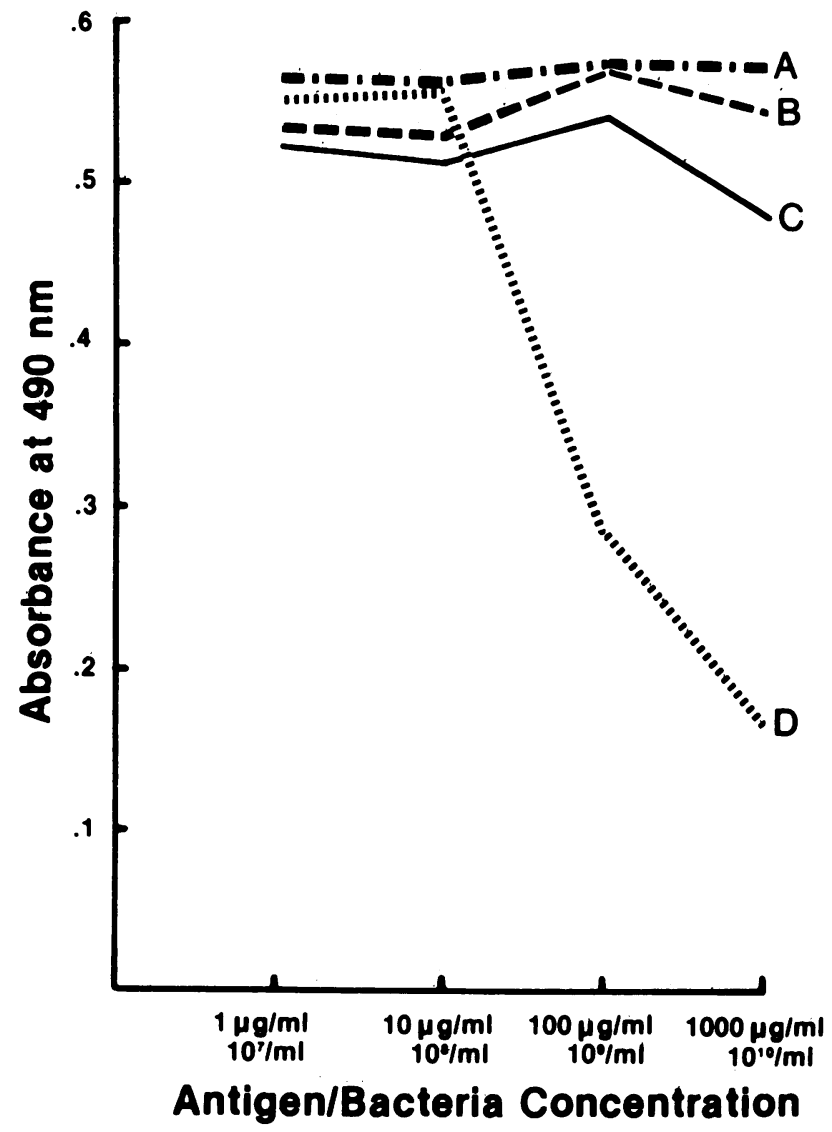

FIG. 2. $A_{490}$ s of anticytotoxic bovine serum samples following adsorption with four concentrations of various $P$. haemolytica antigens. A, Nonadsorbed; B, Formalin-killed P. haemolytica; C, saline extract of $P$. haemolytica; D, cytotoxin.

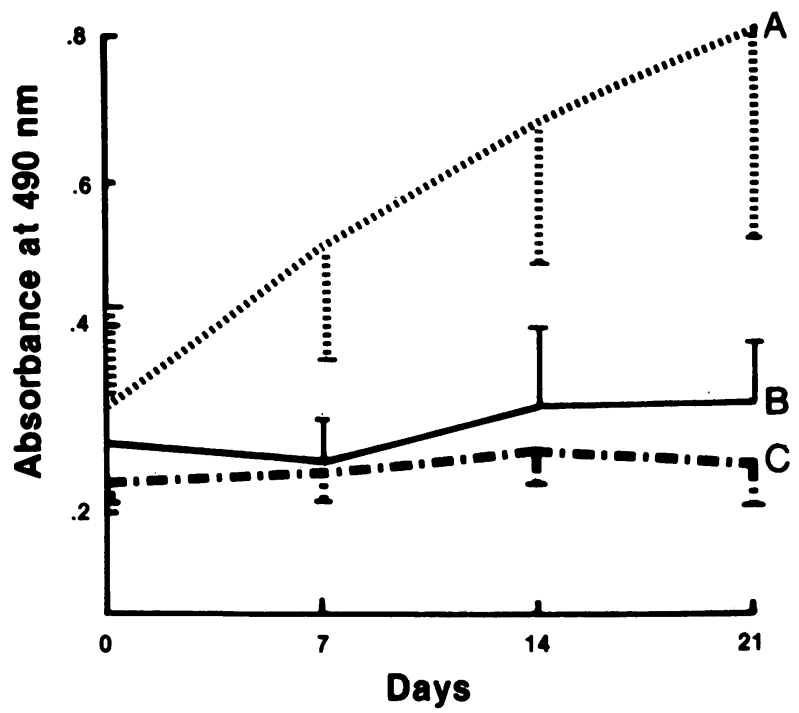

FIG. 3. Mean $A_{490}$ s and standard deviations of serum samples from calves receiving live vaccine (A), bacterin (B), or PBS (controls) (C).

haemolytica antigen. The ELISA results provide information similar to that obtained by cytotoxin neutralization while eliminating the need for serial dilutions of sera, preparation of living cells, and use of radioisotopes.

Preadsorption studies with various $P$. haemolytica antigens demonstrated the specificity of the ELISA reaction for cytotoxin. When preincubated with high concentrations of cytotoxin, antigen-binding sites on immunoglobulins which were specific for cytotoxin apparently became saturated, resulting in a marked decrease in the ELISA absorbance. In contrast, high concentrations of Formalin-killed organisms or saline extracts of $\boldsymbol{P}$. haemolytica had only minimal effects on the ELISA absorbance. These results suggest that cytotoxin is not associated with structural components of the bacteria and further supports its classification as a true exotoxin (25).

Evaluation of the cytotoxin-neutralizing ability of sera from feedlot cattle demonstrated significantly lower cytotoxin-neutralizing activity in the sera of cattle that died of fibrinous pneumonia than in the sera of cattle that died for other reasons (24). Similar associations between pneumonia and cytotoxin neutralization were found in studies of experimentally induced disease $(4,14)$. A direct positive correlation was demonstrated between resistance to experimental challenge with $\boldsymbol{P}$. haemolytica and serum cytotoxin neutralization titers (14). As determined by a modified indirect complement fixation test, however, antibodies to somatic antigens of $\boldsymbol{P}$. haemolytica appeared to be unrelated to the development of pneumonia (4).

The results of this study support these findings and suggest that exposure to live organisms or vaccines containing cytotoxic antigens may be necessary to produce an anticytotoxic immune response and that this response is a better predictor of resistance to pneumonia than the immune response to somatic antigens. ELISA cytotoxin antibody responses and cytotoxin neutralization titers for the livevaccine group were both significantly higher than those for the bacterin group. In association with this, mean lesion scores for the live-vaccine group were significantly lower 
TABLE 1. Antibody responses and lesion scores for cattle challenged with $P$. haemolytic $a^{a}$

\begin{tabular}{|c|c|c|c|c|}
\hline \multirow[b]{2}{*}{ Group } & \multicolumn{4}{|c|}{ Mean \pm SD } \\
\hline & $\begin{array}{c}\text { ELISA } \\
\text { cytotoxin } \\
\text { antibody } \\
\text { response } \\
\left(A_{490}\right)^{b}\end{array}$ & $\begin{array}{c}\text { Cytotoxin } \\
\text { neutralization } \\
\text { titer }^{c}\end{array}$ & FIAX titer & $\begin{array}{l}\text { Lesion } \\
\text { score }^{d}\end{array}$ \\
\hline PBS & $0.39 \pm 0.18$ & $6.4 \pm 5.1$ & $28.5 \pm 15.1$ & $16.9 \pm 4.5$ \\
\hline Bacterin & $0.30 \pm 0.10$ & $8.5 \pm 5.2$ & $102.7 \pm 88.1$ & $10.3 \pm 5.4$ \\
\hline Live vaccine & $0.70 \pm 0.22$ & $88.0 \pm 36.4$ & $173.2 \pm 46.7$ & $3.7 \pm 2.5$ \\
\hline
\end{tabular}

(indicating greater resistance) than those for controls or the bacterin group. The most significant correlation with lesion scores was obtained with cytotoxin neutralization titers, suggesting this to be the test of choice in experimental trials with small sample sizes. For rapid analysis of large numbers of serum samples, however, the ELISA is an excellent alternative.

The relationship between the antigens of $P$. haemolytica and resistance to disease is becoming more clearly defined. Bacterins stimulate a somatic antibody response which does not consistently provide protection from disease and in some cases has been incriminated in enhancing disease $(13,27)$. In the current study, there was a significant reduction in the lesion scores of bacterin-vaccinated animals as compared with controls, however, indicating that some degree of protection may have been afforded by antibodies to somatic antigens. Alternatively, this reduction may have been caused by the presence of low levels of anticytotoxin antibodies or antibodies to somatic antigens which cross-react with cytotoxic antigens. Animals which received live vaccine and possessed high levels of cytotoxin antibodies determined by the ELISA and neutralization assays had lesion scores which were significantly lower (indicating greater resistance) than those for the bacterin group. Although additional protection was associated with increased levels of anticytotoxin antibodies, animals with good neutralization titers or ELISA cytotoxin antibody responses occasionally still developed severe pneumonic lesions. The reasons or factors involved in these cases are unknown.

The pathogenesis of pneumonic pasteurellosis is complex. A successful product for immunologic prevention of the disease will most likely have to take into account multiple antigenic features of Pasteurella spp. The ELISA described

TABLE 2. Regression analysis of antibody responses and lesion scores ${ }^{a}$

\begin{tabular}{|c|c|c|c|c|c|c|}
\hline \multirow[t]{2}{*}{ Parameter } & \multicolumn{2}{|c|}{$\begin{array}{c}\text { Cytotoxin } \\
\text { neutralization } \\
\text { titer }\end{array}$} & \multicolumn{2}{|c|}{ FIAX titer } & \multicolumn{2}{|c|}{ Lesion score } \\
\hline & $r$ & $P$ & $r$ & $P$ & $r$ & $P$ \\
\hline $\operatorname{ELISA}\left(A_{490}\right)$ & 0.675 & 0.0001 & 0.425 & 0.0097 & -0.509 & 0.0015 \\
\hline $\begin{array}{l}\text { Cytotoxin } \\
\text { neutralization } \\
\text { titer }\end{array}$ & & & 0.662 & 0.0001 & -0.605 & 0.0001 \\
\hline FIAX titer & & & & & -0.473 & 0.0036 \\
\hline
\end{tabular}

${ }^{a}$ Pearson product-moment. in this report provides a helpful tool for more clearly defining the role played by cytotoxin in pneumonic pasteurellosis.

\section{ACKNOWLEDGMENTS}

This work was supported in part by special grant 83-CRSR-2-2195 from the U.S. Department of Agriculture.

We thank Diana Moffeit for typing the manuscript and René Simons, Janet Durham, Sharon Oltjen, and Susan Antone for comments and technical assistance.

\section{LITERATURE CITED}

1. Amstutz, H. E., L. A. Horstmaan, and R. L. Morter. 1981. Clinical evaluation of the efficacy of Haemophilus somnus and Pasteurella sp. bacterins. Bovine Pract. 16:106-108.

2. Balyut, C. S., R. R. Simonson, W. J. Bemrick, and S. K. Maheswaran. 1981. Interaction of Pasteurella haemolytica with bovine neutrophils: identification and partial characterization of a cytotoxin. Am. J. Vet. Res. 42:1920-1926.

3. Burrells, C., H. B. Evans, and A. M. Dawson. 1983. Antigenic relationships between the serotypes of Pasteurella haemolytica demonstrable by enzyme-linked immunosorbent assay (ELISA). Vet. Microbiol. 8:187-198.

4. Cho, H. J., J. G. Bohac, W. D. G. Yates, and H. Bieléfeldt Ohmann. 1984. Anticytotoxin activity of bovine sera and body fluids against Pasteurella haemolytica A1 cytotoxin. Can. J. Comp. Med. 48:151-155.

5. Collier, J. R. 1968. Pasteurellae in bovine respiratory disease. J. Am. Vet. Med. Assoc. 152:824-828.

6. Confer, A. W., J. C. Fox, P. R. Newman, G. W. Lawson, and R. E. Corstvet. 1983. A quantitative fluorometric assay for the measurement of antibody to Pasteurella haemolytica in cattle. Can. J. Comp. Med. 47:37-42.

7. Confer, A. W., B. A. Lessley, R. J. Panciera, R. W. Fulton, and J. A. Kreps. 1985. Serum antibodies to antigens derived from a saline extract of Pasteurella haemolytica: correlation with resistance to experimental bovine pneumonic pasteurellosis. Vet. Immunol. Immunopathol. 10:265-278.

8. Confer, A. W., R. J. Panciera, R. E. Corstvet, J. A. Rummage, and R. W. Fulton. 1984. Bovine pneumonic pasteurellosis: effect of culture age of Pasteurella haemolytica used as a live vaccine. Am. J. Vet. Res. 45:2543-2545.

9. Confer, A. W., R. J. Panciera, and R. W. Fulton. 1984. Effect of prior natural exposure to Pasteurella haemolytica on resistance to experimental bovine pneumonic pasteurellosis. Am. J. Vet. Res. 45:2622-2624.

10. Confer, A. W., R. J. Panciera, R. W. Fulton, M. J. Gentry, and J. A. Rummage. 1985. Effect of vaccination with live or killed Pasteurella haemolytica on resistance to experimental bovine pneumonic pasteurellosis. Am. J. Vet. Res. 46:342-347.

11. Corstvet, R. E., R. J. Panciera, and P. Newman. 1978. Vaccination of calves with Pasteurella multocida and Pasteurella haemolytica. Proc. Am. Assoc. Vet. Lab. Diagn. 21:67-90.

12. Donachie, W., C. Burrells, and A. M. Dawson. 1979. Specificity of the enzyme-linked immunosorbent assay (ELISA) for antibodies in the sera of specific pathogen-free lambs vaccinated with Pasteurella haemolytica antigens. Vet. Microbiol. 8:199-205.

13. Friend, S. C., R. G. Thomson, and B. N. Wilkie. 1977. Pulmonary lesions induced by Pasteurella haemolytica in cattle. Can. J. Comp. Med. 41:219-223.

14. Gentry, M. J., A. W. Confer, and R. J. Panciera. 1985. Serum neutralization of cytotoxin from Pasteurella haemolytica, serotype 1 and resistance to experimental bovine pneumonic pasteurellosis. Vet. Immunol. Immunopathol. 9:239-250.

15. Gentry, M. J., R. E. Corstvet, and R. J. Panciera. 1982. Extraction of capsular material from Pasteurella haemolytica. Am. J. Vet. Res. 43:2070-2073.

16. Jensen, R., R. E. Pierson, P. M. Braddy, D. A. Saari, L. H. Lauerman, J. J. England, H. Keyvanfar, J. R. Collier, D. P. Horton, A. E. McChesney, A. Benitez, and R. M. Christie. 1976. Shipping fever in yearling feedlot cattle. J. Am. Vet. Med. Assoc. 169:500-506. 
17. Lillie, L. E. 1974. The bovine respiratory disease complex. Can. Vet. J. 15:233-242.

18. Martin, S. W. 1983. Vaccination: is it effective in preventing respiratory disease or influencing weight gains in feedlot calves? Can. Vet. J. 24:10-19.

19. Martin, S. W., A. H. Meek, D. G. Davis, R. G. Thomson, J. A. Johnson, A. Lopez, L. Stephens, R. A. Curtis, J. F. Prescott, S. Rosendal, M. Savan, A. J. Zubaidy, and M. R. Bolton. 1980. Factors associated with mortality in feedlot cattle: the Bruce County beef cattle project. Can. J. Comp. Med. 44:1-10.

20. Morter, R. L., H. E. Amstutz, and R. A. Crandell. 1982. Clinical evaluation of prophylactic regimens for bovine respiratory disease. Bovine Pract. 17:56-58.

21. Panciera, R. J., and R. E. Corstvet. 1984. Bovine pneumonic pasteurellosis: a model for Pasteurella haemolytica- and Pasteurella multocida-induced pneumonia in cattle. Am. J. Vet. Res. 45:2532-2537.

22. Panciera, R. J., R. E. Corstvet, A. W. Confer, and C. N. Gresham. 1984. Bovine pneumonic pasteurellosis: effect of vaccination with live Pasteurella species. Am. J. Vet. Res. 45:2538-2542.

23. Shewen, P. E., and B. N. Wilkie. 1982. Cytotoxin of Pasteurella haemolytica acting on bovine leukocytes. Infect. Immun. 35:91-94.

24. Shewen, P. E., and B. N. Wilkie. 1983. Pasteurella haemolytica cytotoxin neutralizing activity in sera from Ontario beef cattle. Can. J. Comp. Med. 47:497-498.

25. Shewen, P. E., and B. N. Wilkie. 1985. Evidence for the Pasteurella haemolytica cytotoxin as a product of actively growing bacteria. Am. J. Vet. Res. 46:1212-1214.

26. Smith, P. H., B. Ziola, and P. H. G. Stockdale. 1983. Solid-phase enzyme immunoassay of bovine antibody responses following immunization against and natural infection with Pasteurella haemolytica. Vet. Immunol. Immunopathol. 5:33-45.

27. Wilkie, B. N, R. J. F. Markham, and P. E. Shewen. 1980. Response of calves to lung challenge exposure with Pasteurella haemolytica after parenteral or pulmonary immunization. Am. J. Vet. Res. 41:1773-1778. 